\title{
Taichi Softball as a Novel Chinese Health-Promoting Exercise for Physical Health: A Systematic Review and Meta-Analysis
}

\author{
Liye Zou1,2, Huiru Wang3*, Mark Zhang4, Zhongjun Xiao5 , Qun Fang² \\ ${ }^{1}$ Department of Exercise Science, Physical Education, and Wellness, Tennessee Tech University, Cookeville, TN, USA \\ ${ }^{2}$ Department of Physical Education and Health Education, Springfield College, Springfield, MA, USA \\ ${ }^{3}$ Department of Physical Education, Shanghai Jiao Tong University, Shanghai, China \\ ${ }^{4}$ Department of Sport Management, Delaware State University, Dover, DE, USA \\ ${ }^{5}$ Department of Foreign Language, Jishou University, Jishou, China \\ Email: *wanghrsjtu@163.com
}

How to cite this paper: Zou, L.Y., Wang, H.R., Zhang, M., Xiao, Z.J. and Fang, Q. (2017) Taichi Softball as a Novel Chinese Health-Promoting Exercise for Physical Health: A Systematic Review and Meta-Analysis. Open Journal of Preventive Medicine, 7, 15-31.

https://doi.org/10.4236/ojpm.2017.72002

Received: January 2, 2017

Accepted: February 5, 2017

Published: February 8, 2017

Copyright $\odot 2017$ by authors and Scientific Research Publishing Inc. This work is licensed under the Creative Commons Attribution International License (CC BY 4.0).

http://creativecommons.org/licenses/by/4.0/

\begin{abstract}
Background: Taichi softball was voted as one of the most popular healthpromoting exercises in the category of ball games, which is attributed to that Taichi softball is not only beneficial for lower extremity-related physical health (e.g., balance, leg strength, and flexibility), but can also develop manipulative skill and hand-eye coordination (eating, bathing, dressing, bathing required manipulative skills, grips movement and strength). However, the positive effects of Taichi softball on physical health have rarely been investigated. Therefore, the purpose of this systematic review was to evaluate the effect of Taichi softball on physical health. Methods: Five electronic databases were used to conduct literature searches. Two review authors independently extracted data in a standardized manner. The methodological quality of studies included was independently evaluated according to the Cochrane Collaboration's for Assessing Risk of Bias from the Cochrane Handbook for Systematic Review Interventions. The standard mean difference (SMD) and 95\% confidence interval (CI) using more conservative random effects model were calculated. Results: The sample size of 411 participants ranged from 32 to 150 in the RCTs, along with a wide age range from 18 to 75 . The length of Taichi softball intervention periods in the eligible studies ranged from 12 weeks to 12 months. The participants in the studies consisted of healthy college students, patients with Type 2 diabetes, and older adults from community centers. Six randomized controlled trials were used for the meta-analysis. The aggregated results are in favor of Taichi softball on improving physical health in participants with healthy status and Type 2 Diabetes Mellitus. The improvement on the primary components of the physical health consisted of handgrip strength
\end{abstract}


(SMD, $-0.6,95 \% \mathrm{CI}-0.84$ to $0.36, \mathrm{p}<0.00001)$, trunk flexibility (SMD, -0.4 , $95 \% \mathrm{CI}-0.74$ to $-0.05, \mathrm{p}=0.03$ ), static (SMD, $-0.73,95 \% \mathrm{CI}-0.94$ to -0.51 , $\mathrm{p}<0.00001)$ and dynamic balance (SMD, $-0.68,95 \% \mathrm{CI}-1.2$ to $-0.17, \mathrm{p}=$ 0.009). Conclusions: Taichi softball appears to be beneficial for improving physical health (hand strength, physical balance, flexibility, aerobic endurance, resting heart rate, diastolic and systolic pressures) among healthy adults and patients with Type 2 Diabetes. However, because of the low methodological quality of assessment, ill-designed experimental designs, and small study size, a definite conclusion of Taichi softball improving physical health can be confirmed along with high-quality studies with long follow-up.

\section{Keywords}

Taichi Softball, Health, Diabetes Mellitus

\section{Introduction}

Physical health is defined as a state of physical well-being in which an individual is physically fit to perform their activities without restriction [1]. It is closely associated with components of physical fitness (e.g., cardiovascular endurance, muscular strength, muscular endurance, flexibility, body composition, balance, and coordination) [2]. However, with the scientific and technological progress, physical health in adults was reported to become worse, which may be attributed to their sedentary lifestyles through spending a great amount of time on the digital devices [3] [4] [5] [6]. For example, a long-term sedentary lifestyle was associated with degeneration of trunk flexibility [7] [8] [9] and balance [8] [9] [10]. Individuals with weak trunk flexibility and balance are significantly restricted to perform voluntary movements (e.g. trunk bending to pick up something on the floor). Individuals with trunk mobility limitation are able to complete the voluntary actions, but compensation usually emerges which can distort correct movement patterns leading to musculoskeletal injuries. In addition, adults with the sedentary lifestyle may be more likely to have chronic diseases (e.g., Type 2 with Diabetes mellitus) [11] [12] [13].

Taichi Quan was extensively approved to promote physical health in adults [14] [15] [16] [17] [18].

Taichi softball is a novel Chinese health-enhancing exercise invented based on the principle of Taichi Quan (practice slow, gentle, graceful movements along with deep breathing and relaxation for cultivating internal energy) [19]. Taichi softball was also voted as one of the most popular health-promoting exercises in the category of ball games [20]. Practitioners are required to hold a racquet controlling a light softball while performing Taijiquan movements [19]. Therefore, practicing Taichi softball is not only beneficial for lower extremity-related physical health (balance, leg strength, and flexibility) [21] [22], but can also develop manipulative skill and hand-eye coordination (eating, bathing, dressing, bathing required manipulative skills, grips movement and strength) [23] [24]. These 
components of physical health are critical for people to independently perform daily activities. Physical health benefits can be obtained from practicing Taichi softball and TaijiQuan, but when compared to TaijiQuan, Taichi softball is more enjoyable because it is an interactive exercise [19]. Regardless of these characteristics of Taichi softball contributing to physical health, a comprehensive systematic review investigating Taichi softball for physical health has not been done. The authors of the present study carried out a systematic review and meta-analysis to examine Taichi softball as an intervention to improve physical health.

\section{Methods}

\subsection{Registration}

This research protocol was registered with the International Prospective Register of Systematic Reviews (PROSPERO) on 15 March 2016 (CRD42016036469) [25]. In addition, The Preferred Reporting Items for Systematic Review and Meta-Analysis Protocols (PRISMA-P) 2015 statement was consulted and provided the structure for this review [26].

\subsection{Data Sources and Searches}

Five electronic databases (PubMed, GoogleScholar, Chinese National Knowledge Infrastructure, Chinese Scientific Journal Database, Chinese Biomedical Literature Database $[\mathrm{CBM}]$ ) were used to conduct literature searches, along with the combination strategy of: Taichi ball, Taichi softball, Taiji ball, or Taichi softball. The studies were included if they met the following criteria: 1) only peer-reviewed studies in English or Chinese because reviewer authors are proficient in both languages; 2) original randomized controlled studies published from September 2000 to February 2016; 3) Taichi softball as the main intervention in the studies; 4) a minimum of one component relating to handgrip strength, balance, or trunk flexibility as primary outcomes. Except the primary outcomes, other components of the physical health (e.g., systolic and diastolic pressures, resting heart rate, aerobic endurance, shoulder mobility, and bone mineral density and metabolism) were also reported. In addition, because of the limited number of randomized controlled trials carried out, additional study designs investigating the effectiveness of Taichi softball were also displayed to obtain a more comprehensive understanding (Table 1), including non-randomized controlled studies [23] [27] [28], non-controlled observational studies [29] [30], and cross-sectional studies [31].

\subsection{Data Sources and Searches}

For each included study, two reviewer authors ( $\mathrm{xx}$ and $\mathrm{xx}$ ) independently extracted data in a standardized way. The data extraction included the following: the first author, year of publication, sample size, intervention duration and frequency, and details of the control group, sex and age of study participants, study design, and components of the physical health consisting of primary outcome measures (hand-grip strength, balance, or trunk flexibility), secondary outcomes 
Table 1. Summary of Taiji softball studies in the systematic review.

\begin{tabular}{|c|c|c|c|c|c|c|}
\hline $\begin{array}{c}\text { Author, } \\
\text { year }\end{array}$ & $\begin{array}{l}\text { Study } \\
\text { design }\end{array}$ & $\begin{array}{l}\text { Sample } \\
(\mathrm{F} / \mathrm{M})\end{array}$ & $\begin{array}{l}\text { Age, } \\
\text { mean } \pm S D \\
\text { years }\end{array}$ & $\begin{array}{l}\text { Study groups } \\
\text { (n) }\end{array}$ & $\begin{array}{l}\text { Frequency and } \\
\text { duration }\end{array}$ & Outcomes measured and results \\
\hline $\begin{array}{l}\text { Cui et } \\
\text { al., } 2012\end{array}$ & CSS & $\begin{array}{c}29(29 / 0) \\
\text { Healthy }\end{array}$ & $\begin{array}{l}66.8 \pm 4.36 \\
\quad(\mathrm{~T}) \\
65.6 \pm 3.92 \\
\quad(\mathrm{C})\end{array}$ & $\begin{array}{l}\mathrm{T}(15) \\
\text { No training } \\
\quad(14)\end{array}$ & $\begin{array}{l}\text { T group: Three } \\
60 \text {-minute Taiji } \\
\text { softball sessions } \\
\text { for more than one } \\
\text { year } \\
\text { C: no active sport } \\
\text { participation }\end{array}$ & $\begin{array}{l}\text { Primary outcome (handgrip strength test, } \\
\mathrm{p}<0.05 \text { ) } \\
\text { Additional outcomes (reaction time for } \\
\text { red and green lights, } \mathrm{p}<0.01 \text { and } \\
\mathrm{p}<0.05 \text {, respectively; right hand } \\
\text { stability, } \mathrm{p}<0.01 \text { ) }\end{array}$ \\
\hline $\begin{array}{l}\text { Lam et } \\
\text { al., } \\
2011 \mathrm{a}, \mathrm{b}\end{array}$ & NRCT & $\begin{array}{l}66(39 / 27) \\
\text { Sedentary }\end{array}$ & $\begin{array}{l}\text { Mean age } \\
\text { between } 65 \\
\text { and } 75\end{array}$ & $\begin{array}{c}\mathrm{T}(32) \\
\text { Routine } \\
\text { activities (32) }\end{array}$ & $\begin{array}{l}\text { Two } 60 \text {-minute } \\
\text { Taiji softball } \\
\text { sessions per week } \\
\text { for } 10 \text { weeks }\end{array}$ & $\begin{array}{l}\text { Primary outcomes (flexibility using } \\
\text { sit-and-reach test, } p<0.01 \text {; handgrip } \\
\text { strength test, } p<0.05 \text { ) } \\
\text { Secondary outcomes }(2 \text {-minute step test, } \\
\mathrm{p}<0.01 \text {; time up and go, } \mathrm{p}<0.01 \text { ) } \\
\text { Additional outcomes (arm curls test for } \\
\text { arm muscle strength, } \mathrm{p}<0.01 \text {; AAPERD } \\
\text { Soda Po test for hand eye coordination, } \\
\mathrm{p}<.01 \text {; chair sand test for lower body } \\
\text { strength, } p<0.01 ; \text { back scratch test, } \\
\mathrm{p}<0.01 ; \mathrm{BMI}, \mathrm{p}<0.05 \text { ) }\end{array}$ \\
\hline $\begin{array}{l}\text { Li et al., } \\
2010\end{array}$ & RCT & $\begin{array}{l}64(32 / 32) \\
\text { Healthy college } \\
\text { students }\end{array}$ & $\begin{array}{l}19.5 \pm 2.6(\mathrm{~T}) \\
19.5 \pm 2.3(\mathrm{C})\end{array}$ & $\begin{array}{l}\mathrm{T}(32) \\
\mathrm{C}(32) \text { no } \\
\text { training }\end{array}$ & $\begin{array}{l}\text { Six } 120 \text {-minute } \\
\text { sessions per week } \\
\text { for } 12 \text { weeks }\end{array}$ & $\begin{array}{l}\text { Primary outcomes (handgrip strength, } \\
p<0.05 \text {; flexibility using sit-and-reach } \\
\text { test, } p<0.05 \text {; and stock balance test, } \\
p<0.05\end{array}$ \\
\hline Lai, 2010 & NOT & $\begin{array}{l}17(9 / 8) \\
\text { Healthy older } \\
\text { adults }\end{array}$ & $\begin{array}{l}\text { Aged } \\
\text { between } 60 \\
\text { and } 69\end{array}$ & $\mathrm{~T}(17)$ & $\begin{array}{l}\text { Seven } \\
\text { 60-to-90-minute } \\
\text { taiji softball } \\
\text { sessions for three } \\
\text { and half months }\end{array}$ & $\begin{array}{l}\text { Primary outcomes (flexibility using } \\
\text { sit-and-reach test, } \mathrm{p}<0.05 \text {; handgrip } \\
\text { strength, } \mathrm{p}<0.01 \text {; static balance, }<0.01 \text { ) } \\
\text { Additional outcomes (BMI, } \mathrm{p}<0.01 \text {; } \\
\text { waist-and-hip ratio, } \mathrm{p}<0.0 \text {; shoulder } \\
\text { skinfold, } \mathrm{p}<0.05 \text { abdomen skinfold, } \\
\mathrm{p}<0.01 \text {, waist skinfold, } \mathrm{p}<0.5 \text {; reaction } \\
\text { time } \mathrm{p}<0.05 \text { ) }\end{array}$ \\
\hline $\begin{array}{l}\text { Qiu et } \\
a l ., 2014\end{array}$ & RCT & $\begin{array}{l}150(150 / 0) \\
\text { Healthy college } \\
\text { students }\end{array}$ & $\begin{array}{l}\text { Aged } \\
\text { between } 18 \\
\text { and } 25\end{array}$ & $\begin{array}{c}\mathrm{T}(50) \\
\text { BaDuanJin } \\
(50) \\
\mathrm{C}(50)\end{array}$ & $\begin{array}{l}\text { Five } 50 \text {-minute } \\
\text { Taiji softball } \\
\text { sessions per week } \\
\text { for } 18 \text { weeks }\end{array}$ & $\begin{array}{l}\text { Primary outcomes (handgrip strength, } \\
\mathrm{p}<0.01 \text {; flexibility using sit-and-reach } \\
\text { test, } \mathrm{p}<0.5 \text {; stock balance test, } \mathrm{p}<0.01 \text { ) } \\
\text { Secondary outcomes (systolic and } \\
\text { diastolic pressures, } \mathrm{p}>0.05 \text {; resting } \\
\text { heart rate, } \mathrm{p}<0.05 \text {; step test, } \mathrm{p}<0.01 \text { ) } \\
\text { Additional outcomes (weight, } \mathrm{p}<0.05 \text {; } \\
\text { waist and abdomen circumferences, } \\
\mathrm{p}<0.05 \text {; arm and shoulder skinfolds, } \\
\mathrm{p}<0.01 \text {; abdomen skinfold, } \mathrm{p}<0.01 \text {; } \\
\text { broad long jump, } \mathrm{p}<0.05 \text { ) }\end{array}$ \\
\hline $\begin{array}{l}\text { Wang, } \\
2007\end{array}$ & NRCT & $\begin{array}{c}40(40 / 0) \\
\text { Postmenopausal } \\
\text { women }\end{array}$ & $\begin{array}{l}60 \pm 8(\mathrm{~T}) \\
61 \pm 5(\mathrm{C})\end{array}$ & $\begin{array}{c}\text { T (20); } \\
\text { Walking (20) }\end{array}$ & $\begin{array}{l}\text { Three 50-minute } \\
\text { Taiji softball } \\
\text { sessions per week } \\
\text { for } 24 \text { weeks }\end{array}$ & $\begin{array}{l}\text { Additional outcomes (bone mineral } \\
\text { density on lumbar } 2-4, \mathrm{p}<0.05] \text {; bone } \\
\text { mineral content on lumbar } 2 \text { and femoral } \\
\text { neck, } \mathrm{p}<0.001 \text { ), and bone metabolism } \\
\text { index (bone glaprolein }[\mathrm{BGP} \text { ] and serum } \\
\text { alkaline phosphatase }[\mathrm{ALP}], \mathrm{p}<0.001 \text { ) }\end{array}$ \\
\hline
\end{tabular}


Wei,

2012

RCT

$52(22 / 30)$

Patients with

Type 2 diabetes

32

Xiao et RCT

al., 2015

Patients with

Type 2 diabetes Mellitus

Xiao,

2014

RCT

72 (unclear)

Healthy

community

dwellers

Yao,

$41(41 / 0)$

2008

RCT Healthy older

\section{Mean age \\ 65.5}

(16)
T (26)

Routine drug

treatment

(26) Six 60 -minute
Taiji softball
sessions for 12
weeks
Primary outcomes (handgrip strength, $\mathrm{p}<0.01$; flexibility using sit-and-reach test, $\mathrm{p}<0.01$ )

Secondary outcomes $(\mathrm{p}<0.01$; resting heart rate, $\mathrm{p}<0.01$; systolic and diastolic pressures, $\mathrm{p}<0.05)$

Additional outcomes (BMI, BMI, $\mathrm{p}<0.01$; pulmonary function index, $\mathrm{p}<0.05$; waist-to-hip ratio)

Primary outcomes (static and dynamic balance using Berg balance scale, $\mathrm{p}=0.008$ and Timed Up-and-Go, $\mathrm{p}=0.02$; Handgrip strength, $\mathrm{p}=0.03$; flexibility using chair sit-and-reach, $\mathrm{p}=0.009)$ Secondary outcomes (Time Up-and-Go, $\mathrm{p}=0.02 ; 6$-minute walk test) Additional outcome (right shoulder mobility using back scratch test, $\mathrm{p}=0.046$

Three 60-to-120 minute Taiji softball sessions per week for 12 months

Five 60-minute Taiji softball sessions per week for 6 months

Seven 30-minute Taiji softball sessions for 24 weeks
Primary outcomes (unipedal and tandem stance, $p=0.009$; Time Up-and-Go, $\mathrm{p}=0.03$ )

Primary outcome (Stork balance test, $\mathrm{p}<0.05)$

Primary outcomes (handgrip strength test, $\mathrm{p}<0.05$; sit-and-reach test for flexibility, $\mathrm{p}<0.05$; stock balance test, $\mathrm{p}<0.05)$

Additional outcomes (supine leg raise test for leg strength, $\mathrm{p}<0.05$; shoulder mobility using back scratch test, $\mathrm{p}<0.05$; hip flexibility, $\mathrm{p}<0.05$; agility $\mathrm{T}$ - test, $\mathrm{p}<0.01)$

$\mathrm{T}$ = Taichi softball group; $\mathrm{C}$ = control group; $\mathrm{RCT}$ = Randomized controlled trial; CSS = Cross-sectional trial; NRCT = non-randomized controlled trial; NOT $=$ non-controlled observational trial.

(systolic and diastolic pressures, resting heart rate, aerobic endurance, and mobility), and additional physical health-related components. A third party appeared and had dealt with disagreements between the two reviewers.

With respect to the change scores and standard deviations for the primary and secondary outcomes, if authors did not report the change score data, reviewer $(\mathrm{xxx})$ first tried to contact the authors via email or phone call to obtain the data. In cases where the data was not obtainable, reviewers used one of the following methods: a) if baseline scores between two groups were not significantly different, scores from posttest were used for data analysis; b) if baseline scores were different, reviewers attempted to estimate the change scores and standard devia- 
tion through standard formulas provided by Cochrane Handbook for Systematic Reviews of Interventions [32]. If reviewers were unable to find the relevant information for estimating the change scores and standard deviations, the study was excluded. In addition, the study [33] with two interventions and one control groups, review author combined two group (non-Taichi softball intervention and control group) to create a single pair-wise comparison. The method is recommended by Crochrane Handbook for Systematic Reviews of Interventions 16.5.4. (how to include multiple groups from one study).

\subsection{Assessment of Risk Bias}

The methodological quality of each study was independently evaluated according to the Cochrane Collaboration's for Assessing Risk of Bias from the Cochrane Handbook for Systematic Review Interventions [32]. The type of bias is classified as the following domains: 1) selection bias (sequence generation and allocation concealment); 2) performance bias (blinding of participants and personnel); 3) detection bias (blinding of outcome assessment); 4) attrition bias (incomplete outcome data); 5) reporting bias (selective outcome reporting), and other biases. Judgment of the reviewers on each of seven domains of each included study was based on three categories (low risk of bias, high risk of bias, or unclear risk of bias). The specific requirements of the judgment for each category can be found from Table 8.5. d. of the Cochrane Handbook (criteria for judging risk of bias in the risk of bias assessment tool). A method was used for summary assessment of the risk of bias for each important outcome and across studies on basis of: a) low risk of bias for all key domains ("Low" indicating low risk of bias); b) unclear risk of bias for one or more key domains ("unclear" indicating unclear risk of bias); c) high risk of bias for one or more key domains (high indicating high risk of bias).

\subsection{Statistical Analysis}

Revman 5.3 software within the Cochrane Collaboration for data analysis was used to synthesize a subset of the most commonly reported outcomes from the six randomized controlled trials. The standard mean difference (SMD), along with $95 \%$ confidence interval (CI) using more conservative random effects model, was used to calculate heterogeneity for the primary and secondary continuous outcomes [34]. The value of $\mathrm{I}^{2}$ was used to test heterogeneity across the included studies. Studies with $\mathrm{I}^{2}$ ranging between $25 \%$ and $50 \%$ for low heterogeneity, $\mathrm{I}^{2}$ ranging between $50 \%$ and $75 \%$ for moderate heterogeneity, and $\mathrm{I}^{2}>75 \%$ for high heterogeneity were considered respectively [35]. A funnel plot for the primary outcomes (handgrip strength, trunk flexibility, static and dynamic balance) was used to explore publication bias.

\section{Results}

\subsection{Description of Included Trial}

As displayed in Figure 1, the flow chart reflects the search strategies (search 


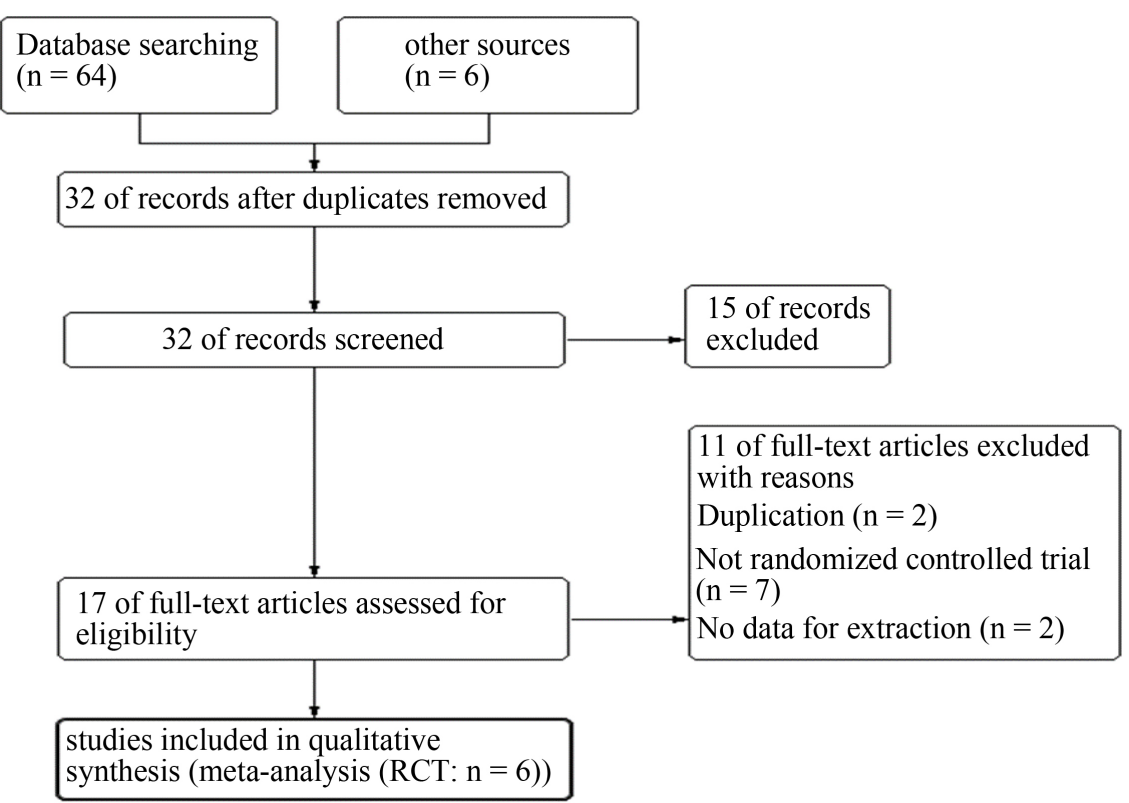

Figure 1. Flowchart showing the retrieval of studies for review.

process and study selection). A total of 70 titles were identified using the following databases: PubMed $(\mathrm{n}=2)$, Google Scholar $(\mathrm{n}=19)$, Chinese National Knowledge Infrastructure $(n=15)$, Chinese Scientific Journal Database $(n=16)$, Chinese Biomedical Literature Database $(n=12)$, and other sources $(n=6)$. After removing 38 duplicates, 32 articles were screened. 15 article were excluded based on two reasons (no relevance $=10$; not a full text article $=5$ ). Full texts of 17 articles were retrieved, and 11 articles were excluded with the following reasons: no components of the physical health reported $(n=4)$, no Taichi softball intervention $(\mathrm{n}=3)$, and incomplete data extraction $(\mathrm{n}=4)$. The final number of six RCTs were included for meta-analysis, including two studies in English [24] [36] and four studies in Chinese [21] [33] [37] [38].

The sample size of 411 participants ranged from 32 to 150 in the RCTs, along with a wide age range from 18 to 75 . The participants in the studies consisted of healthy college students [33] [38], patients with Type 2 diabetes [24] [37], and community dwellers [21] [26]. The control groups either involved no training, [21] [24] [38] jogging and aerobic exercises [26], regular drug treatment [37] or BaduanJin [33], and the participants in the experimental group experienced the Taichi softball program [21] [24] [33] [36] [37] [38]; with an exercise time range from 50-to-120 minute; three-to-six sessions weekly; intervention period ranging from 12 weeks to 12 months. The characteristics of the included articles along with additional relevant non-RCTs [23] [27] [29] [30] [31] [39] were shown in Table 1.

\subsection{Methodological Quality of Included Trials}

As shown in Figure 2, according to the quality assessment criteria (the Cochrane Collaboration's for Assessing Risk of Bias from the Cochrane Handbook for Systematic Review Interventions) [32], the majority of the six RCTs were consi- 
Random sequence generation (selection bias)

Allocation concealment (selection bias)

Blinding of participants and personnel (performance bias)

Blinding of outcome assessment (cetection bias)

Incomplete outcome data (attrition bias)

Selective reporting (reporting bias)

Other bias

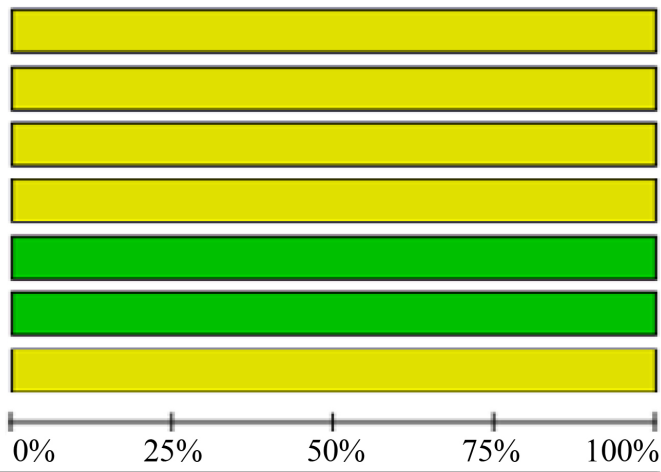

Low risk of bias

Unclear risk of bias

High risk of bias

Figure 2. Risk of bias graph: review authors' judgements about each risk of bias item presented as percentages across all included studies.

dered to be poor methodological quality [21] [24] [33] [36] [37] [38]. Although the randomized allocation of participants in all studies was described, none of the studies included methods of random sequence generation (e.g. referring to a random number table, using a computer random number generator, or coin tossing). Except two items (incomplete outcome data for attrition bias and selective reporting for reporting bias) of all studies with low risk bias [21] [24] [33] [36] [37] [38], the rest of items (allocation concealment, blinding of participants and personnel, blinding of outcome assessment, and other bias) for all studies remained unclear. In order to obtain the original methods about the five items, one of researchers of the present study (HRW) contacted the authors via email that was found on from the contact information listed on the authors publication, but did not receive any response. Six follow-up phone calls via Skype were made. Only two authors answered but stated that they lost the original data.

\subsection{Meta-Analysis of Outcomes Measured}

Outcomes related to physical health were mainly comprised of three primary components with the six RTCs (hand strength, flexibility using sit-and-reach, and balance), along with secondary components (aerobic endurance, resting heart rate, systolic and diastolic pressures) [21] [24] [33] [36] [37] [38]. In order to obtain a more comprehensive understanding, additional components of physical health from non-RCTS [23] [27] [29] [30] [31] [39] were also depicted in Table 1 (e.g., BMI, leg strength, agility, reaction time, aerobic endurance, shoulder mobility, pulmonary function, and bone mineral density).

Four RCTs (a total of participants $=298$ ) reported handgrip strength with handgrip dynamometer [24] [33] [37] [38]. Meta-analyses were performed to compare the Taichi softball program with non-intervention controls [24] [38], Baduanjin (one of the Chinese traditional health-promoting exercises) and non-intervention controls [33], and routine drug treatment [37]. The overall results of these studies suggest that Taichi softball is associated with significantly improved handgrip strength $(\mathrm{SMD}=-0.6,95 \% \mathrm{CI}[-0.84,-0.36]$, P value of 
0.55 for heterogeneity with $\mathrm{I}^{2}=0 \%, \mathrm{P}$ value of test for overall effect $<0.00001$; Figure 3).

Four RCTs (a total of participants $=298$ ) reported flexibility with sit- and-reach test [24] [33] [37] [38]. Meta-analyses were performed to compare Taichi softball program with non-intervention controls [24] [38], Baduanjin (one of Chinese traditional health-promoting exercises) and non-intervention controls [33], and routine drug treatment [37]. The overall results of these studies suggest that Taichi softball is associated with significantly improved trunk flexibility (SMD = $-0.4,95 \% \mathrm{CI}[-0.74,-0.05], \mathrm{P}$ value of 0.13 for heterogeneity with $\mathrm{I}^{2}=47 \%, \mathrm{P}$ value of test for overall effect $=0.03$; Figure 3 ).

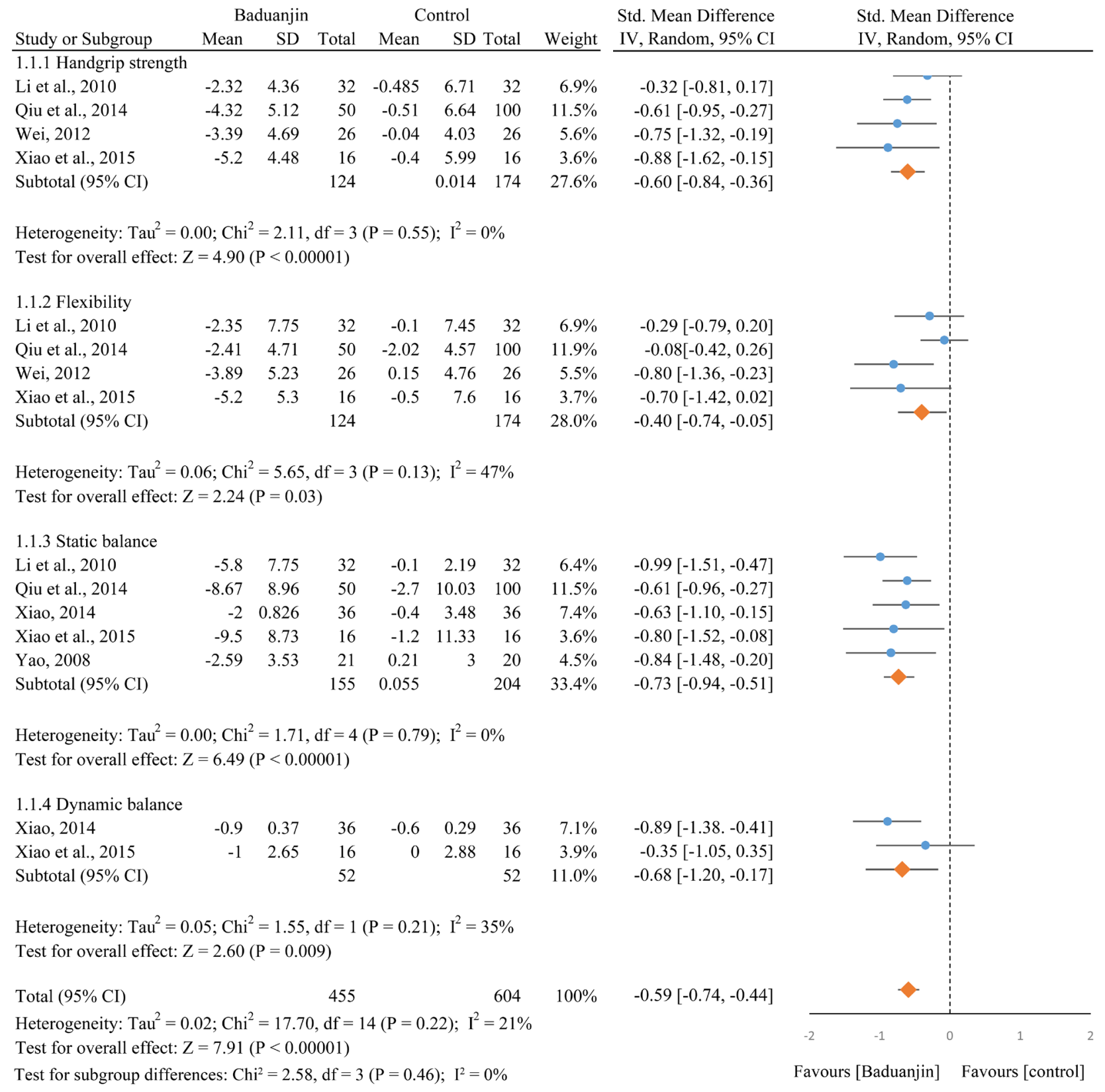

Figure 3. Forest plot showing the effect of Taiji softball on handgrip strength (handgrip dynamometer), flexibility (sit-and-reach test), static (stock standing test) and dynamic balance (timed up and go). 
Five RCTs (a total of participants $=359$ ) reported static balance [21] [24] [33] [36] [38]. Meta-analyses were performed to compare the Taichi softball program with non-intervention controls [21] [24] [38], Baduanjin (one of the Chinese traditional health-promoting exercises) and non-intervention controls [33], and other physical exercise (but the authors did not mention the extract name of the exercise) [36]. The overall results of these studies suggest that Taichi softball is associated with significantly improved balance performance (SMD $=-0.73,95 \%$ CI $[-0.94,-0.51]$, P value of 0.79 for heterogeneity with $\mathrm{I}^{2}=0 \%, \mathrm{P}$ value of test for overall effect $<0.00001$; Figure 3 ).

Two RCTs (a total of participants $=104$ ) reported mobility (dynamic balance) with Timed Up and Go test [24] [36]. Meta-analyses were performed to compare the Taichi softball program with non-intervention controls [24], and exercise (but the authors did not mention the extract name of the exercise) [36]. The overall results of these studies suggest that Taichi softball is associated with significantly improved balance performance (SMD $=-0.68,95 \%$ CI $[-1.2,-0.17], \mathrm{P}$ value of 0.21 for heterogeneity with $\mathrm{I}^{2}=35 \%, \mathrm{P}$ value of test for overall effect $=$ 0.009).

Two RCTs (a total of participants $=182$ ) reported aerobic endurance [24] [33]. Meta-analyses were performed to compare the Taichi softball program with non-intervention controls [24], Baduanjin (one of the Chinese traditional health-promoting exercises) and non-intervention controls [33]. The overall results of these studies suggest that Taichi softball is associated with significantly improved aerobic endurance performance (SMD $=-0.69,95 \%$ CI $[-1.04,-0.34]$, $\mathrm{P}$ value of 0.30 for heterogeneity with $\mathrm{I} 2=9 \%$, P value of test for overall effect $<$ 0.0001 ; Figure 4).

Two RCTs (a total of participants $=202$ ) reported resting heart rate [33] [37]. Meta-analyses were performed to compare the Taichi softball program with non-intervention controls [33], and routine drug treatment [37]. The overall results of these studies suggest that Taichi softball is associated with significantly improved cardiovascular function (SMD $=-1.45,95 \%$ CI $[-1.77,-1.12]$, P value of 1 for heterogeneity with $\mathrm{I}^{2}=0 \%, \mathrm{P}$ value of test for overall effect $<0.00001$; Figure 5)

Two RCTs (a total of participants $=202$ ) reported systolic pressure [33] [37]. Meta-analyses were performed to compare the Taichi softball program with non-intervention controls [33], and routine drug treatment [37]. The overall results of these studies suggest that Taichi softball is associated with significantly decreased systolic pressure (SMD $=-0.24,95 \% \mathrm{CI}[-0.53,-0.05]$, $\mathrm{P}$ value of 0.35 for heterogeneity with $\mathrm{I}^{2}=0 \%, \mathrm{P}$ value of test for overall effect $=0.10$; Figure 6 ). Two RCTs (a total of participants $=202$ ) reported diastolic pressure [33] [37]. Meta-analyses were performed to compare the Taichi softball program with non-intervention controls [31], and routine drug treatment [37]. The overall results of these studies suggest that Taichi softball is associated with significantly decreased diastolic pressure (SMD $=-0.20,95 \% \mathrm{CI}[-0.49,-0.08]$, $\mathrm{P}$ value of 0.43 for heterogeneity with $\mathrm{I}^{2}=0 \%, \mathrm{P}$ value of test for overall effect $=0.17$; Figure 6). 


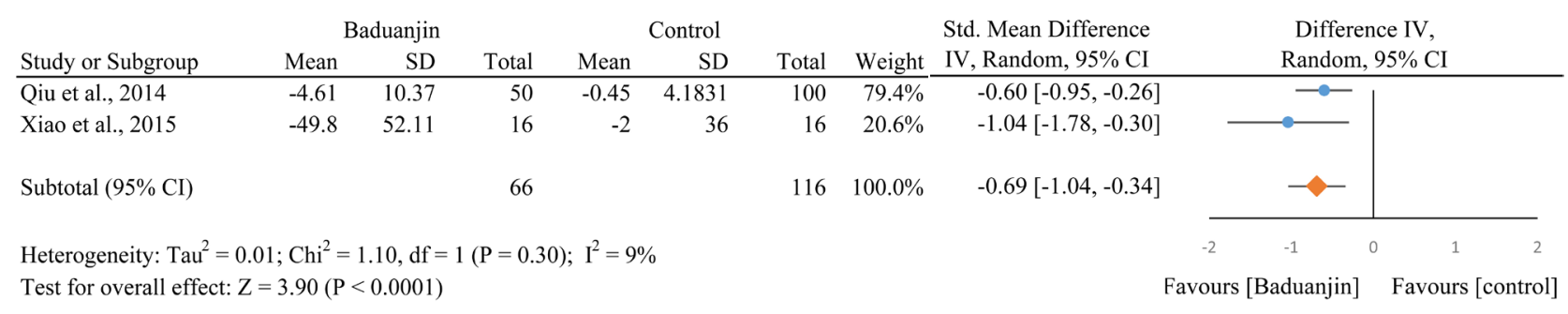

Figure 4. Aerobic endurance was measured using step test and 6-minute walking.

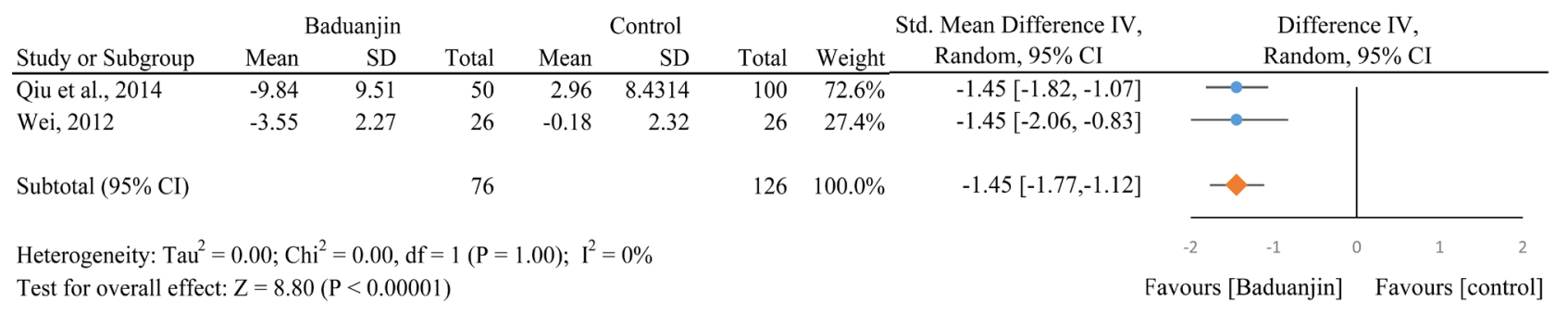

Figure 5. A forest plot of the meta-analysis of RCTs comparing Taiji softball group with control group for change in resting heart rate.

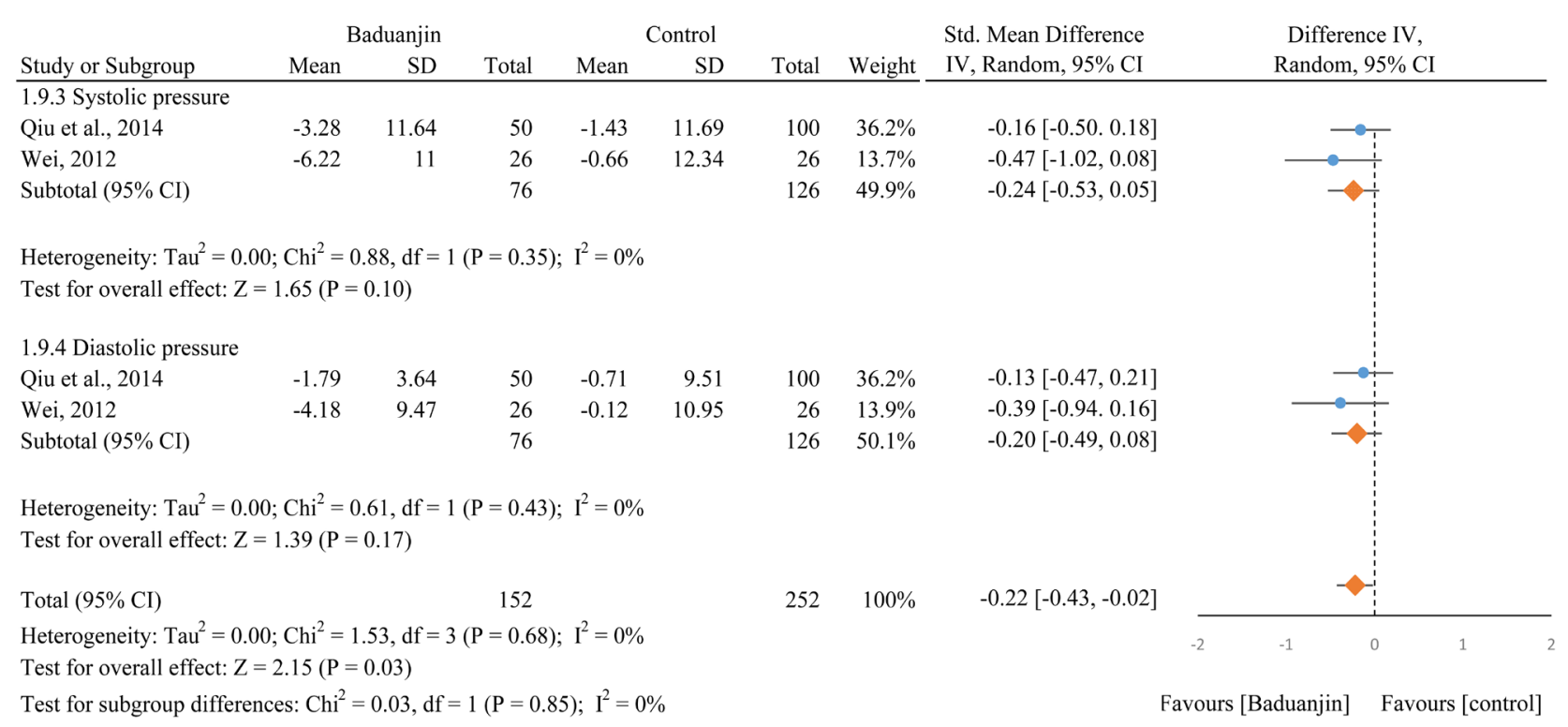

Figure 6. A forest plot of the meta-analysis of RCTs comparing Taiji softball with control group for change in systolic and diastolic pressures.

A funnel plot for the primary outcomes was performed, including handgrip strength ( $\mathrm{n}=4$ RCTs) [24] [29] [30] [31], trunk flexibility ( $\mathrm{n}=4$ RCTs) [24] [33] [37] [38], static $(n=5)$ [21] [24] [33] [36] [38], and dynamic balances $(n=2$ RCTs) [24] [36]. The review authors have difficulty to interpret the positive findings because of the limiting number of RCTs in the current study (Figure 7).

\subsection{Adverse Events}

None of RTCs mentioned adverse effects (e.g. fall, hospitalization, side effects of medication, or death) resulting from participating in Taichi softball program. 


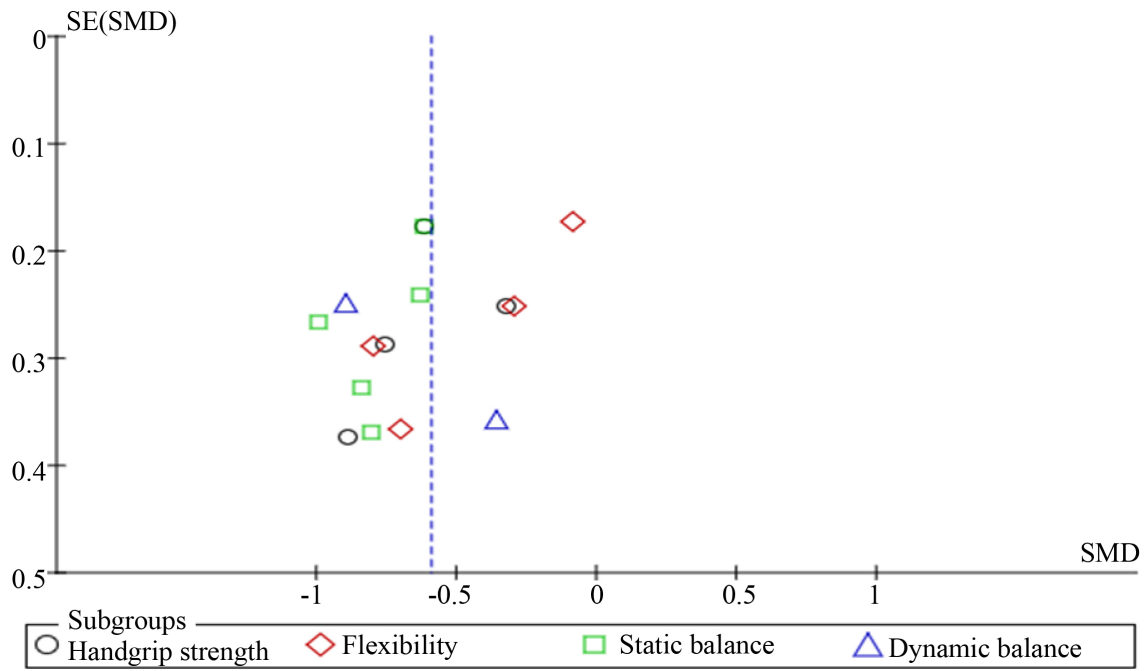

Figure 7. A Funnel plot for handgrip strength, trunk flexibility, static balance, and dynamic balance.

\section{Results}

The purpose of the present meta-analysis was to evaluate the effect of Taichi softball training on physical health in adults. The meta-analysis suggests that Taichi softball training is beneficial for improving physical health (hand strength, physical balance, flexibility, aerobic endurance, resting heart rate, diastolic and diastolic pressures). Taichi softball, as a novel health-enhancing exercise, should be recommended to practice in order to receive physical health benefits, which helps healthy adults to maintain high quality of life [21] [33] [36] [38]. Taichi softball should be available in a rehabilitation program as a nonpharmaceutical alternative method for patients with Type 2 Diabetes [24] [37].

However, although meta-analysis verified that Taichi softball had a positive impact on physical health, two main factors contained the small sample size and poor methodological qualities of included trials that potentially weakened positive findings. The authors therefore should conservatively interpret the positive findings. The methodological quality of the included randomized controlled trials was evaluated based on five main aspects with seven items [32]. Overall result of judgment for each included trial was considered to be high risk of bias, which is mainly attributed to inadequate information in the following: 1) process of random sequence generation (e.g., although the authors described that participants were randomly allocated into two groups, but none of random components were mentioned such as computer random number generator, coin tossing, or throwing dice; 2) allocation concealment (selection bias) 3) blinding of participants and personnel (performance bias) 4) blinding of outcome assessment (detection bias). Only two studies included conducted a pre-experimental estimation of sample size and power [24] [36]. Therefore, results from poor experimental design are not as convincible as a well-designed experiment produced results [40].

When compared to TaijiQuan as a low-limb dominant exercise (e.g., balance, 
and leg strength) [17] [40] [41] [42], Taichi softball does not only require low extremity-related abilities, but also the abilities (strong handgrip strength holding the racket to control the softball, shoulder mobility, and eye-hand coordination as two main abilities are essential) are needed [19]. In this way, Taichi softball may relatively require practitioners to have better abilities. Therefore, researchers should pay more attention to safety of participating in Taichi softball. As a novel Chinese health-enhancing exercise, occurrence of adverse events during Taichi softball intervention period should be recorded such as death, hospitalization required, participants forced to leave because of a permanent adverse outcome, or a fall leading to bone fracture. In addition, minor adverse events should also be documented with a diary such as muscle soreness or pain lasting three days after a Taichi softball session, and dizziness or faintness during a Taichi softball session. Nevertheless, none of the included trials mentioned any adverse events. Therefore, the present systematic review is unable to draw a conclusion regarding the safety of Taichi softball, suggesting that future studies examining the efficacy of Taichi softball should take into account documentation of adverse events.

Although no withdrawals were found in the included studies, weekly session attendances were not reported at all [21] [24] [33] [36] [37] [38]. Participants adhering to the Taichi softball program throughout the entire intervention period would produce different results when compared to participants with the absence of Taichi softball sessions [43] [44] [45]. Strategy dealing with missing Taichi softball sessions (e.g. participants missing more than six consecutive sessions should be contacted and asked to make up) was not reported [21] [24] [33] [36] [37] [38]. In addition, with respect to post-intervention follow-up, it should be used to investigate duration of Taichi softball maintaining physical health [46] [47], but was not reported in all RCTs [21] [24] [33] [36] [37] [38].

\section{Conclusion}

The statistical significance in the meta-analysis indicates that Taichi softball participants with healthy status and Type 2 Diabetes Mellitus can obtain physical health benefits. However, because of low methodological quality of assessment and ill-designed experimental designs, definite conclusion of Taichi softball improving physical health can be confirmed along with high-quality studies with long follow-up.

\section{Acknowledgements}

The authors would like to thank the librarians from Springfield College (USA), with use of inter-library loan. The relevant articles were obtained for this first review paper examining the effect of Tai Chi softball for health benefits.

\section{Conflict of Interests}

The authors declare that they have no other conflict of interests. 


\section{Funding}

No financial support was received for the conduct of this study or preparation of this manuscript.

\section{References}

[1] World Health Organization (2006) The World Health Report: Working Together for Health. 45th Edition, Supplement. http://www.who.int/governance/eb/who_constitution_en.pdf

[2] Corbin, C.B., Pangrazi, R.P. and Franks, B.D. (2008) Definition: Health, Fitness and Physical Activity. President's Council on Physical Fitness and Sports Research Digest, 3, 1-8.

[3] Lepp, A., Barkley, J.E., Sanders, G.J., Rebold, M. and Gates, P. (2013) The Relationship between Cell Phone Use, Physical and Sedentary Activity, and Cardiorespiratory Fitness in a Sample of US College Students. International Journal of Behavioral Nutrition and Physical Activity, 10, 79. https://doi.org/10.1186/1479-5868-10-79

[4] Owen, N., Healy, G.N., Matthews, C.E. and Dunstan, D.W. (2010) Too Much Sitting: The Population-Health Science of Sedentary Behavior. Exercise and Sport Sciences Reviews, 38, 105. https://doi.org/10.1097/JES.0b013e3181e373a2

[5] Anderson, M.A. (2015) Technology Device Ownership: 2015. Pew Research Center, Internet, Science and Technology.

http://www.pewinternet.org/2015/10/29/technology-device-ownership-2015/

[6] King, A.C., Goldberg, J.H. and Salmon, J. (2010) Correlates of Prolonged Television Viewing Time in US Adults to Inform Program Development. American Journal of Preventive Medicine, 38, 17-26.

[7] Evenson, K.R. (2012) Objective Measurement of Physical Activity and Sedentary Behavior among US Adults Aged 60 Years or Older. Preventing Chronic Disease, 9 , Article ID: 110109.

[8] Ceceli, E., Gökoglu, F., Köybasi, M., Çiçek, Ö. and Yorgancioglu, Z.R. (2009) The Comparison of Balance, Functional Activity, and Flexibility Between Active and Sedentary Elderly. Topics in Geriatric Rehabilitation, 25, 198-202. https://doi.org/10.1097/01.TGR.0000359394.19270.57

[9] Graciosa, M.D., Coelho, J.J., da Costa, L.M.R., de Medeiros, D.L., Martinello, M. and Ries, L.G.K. (2013) Effect of Sedentary Lifestyle, Nutritional Status and Sex on the Flexibility of School Children. Revista Brasileira de Crescimento e Desenvolvimento Humano, 23, 144-150. https://doi.org/10.7322/jhgd.61280

[10] Michael, K.M., Allen, J.K. and Macko, R.F. (2005) Reduced Ambulatory Activity After Stroke: The Role of Balance, Gait, and Cardiovascular Fitness. Archives of Physical Medicine and Rehabilitation, 86, 1552-1556. https://doi.org/10.1016/j.apmr.2004.12.026

[11] Hu, F.B., Li, T.Y., Colditz, G.A., Willett, W.C. and Manson, J.E. (2003) Television Watching and Other Sedentary Behaviors in Relation to Risk of Obesity and Type 2 Diabetes Mellitus in Women. Journal of the American Medical Association, 289, 1785-1791. https://doi.org/10.1001/jama.289.14.1785

[12] Hu, F.B., Leitzmann, M.F., Stampfer, M.J., Colditz, G.A., Willett, W.C. and Rimm, E.B. (2001) Physical Activity and Television Watching in Relation to Risk for Type 2 Diabetes Mellitus in Men. Archives of Internal Medicine, 161, 1542-1548. https://doi.org/10.1001/archinte.161.12.1542

[13] Hu, F.B., Manson, J.E., Stampfer, M.J., Colditz, G., Liu, S., Solomon, C.G. and Wil- 
lett, W.C. (2002) Diet, Lifestyle, and the Risk of Type 2 Diabetes Mellitus in Women. Obstetrical \& Gynecological Survey, 57, 162-164. https://doi.org/10.1097/00006254-200203000-00018

[14] Wolf, S.L., Barnhart, H.X., Kutner, N.G., McNeely, E., Coogler, C. and Xu, T. (1996) Reducing Frailty and Falls in Older Persons: An Investigation of Tai Chi and Computerized Balance Training. Journal of the American Geriatrics Society, 44, 489-497. https://doi.org/10.1111/j.1532-5415.1996.tb01432.x

[15] Wolfson, L., Whipple, R., Derby, C., Judge, J., King, M., Amerman, P. and Smyers, D. (1996) Balance and Strength Training in Older Adults: Intervention Gains and Tai Chi Maintenance. Journal of the American Geriatrics Society, 44, 498-506. https://doi.org/10.1111/j.1532-5415.1996.tb01433.x

[16] Hong, Y., Li, J.X. and Robinson, P.D. (2000) Balance Control, Flexibility, and Cardiorespiratory Fitness among Older Tai Chi Practitioners. British Journal of Sports Medicine, 34, 29-34. https://doi.org/10.1136/bjsm.34.1.29

[17] Song, R., Lee, E.O., Lam, P. and Bae, S.C. (2003) Effects of Tai Chi Exercise on Pain, Balance, Muscle Strength, and Perceived Difficulties in Physical Functioning in Older Women with Osteoarthritis: A Randomized Clinical Trial. Journal of Rheumatology, 30, 2039-2044.

[18] Taylor-Piliae, R.E., Haskell, W.L., Stotts, N.A. and Froelicher, E.S. (2006) Improvement in Balance, Strength, and Flexibility after 12 Weeks of Tai Chi Exercise in Ethnic Chinese Adults with Cardiovascular Disease Risk Factors. Alternative Therapies, Health and Medicine, 12, 50-58.

[19] Bai, R. (2008) Taiji Softball. Physical Education Press, Being.

[20] Favorite Sports. http://sd.sina.com.cn/iframe/212/sdjsvote_880.html

[21] Yao, Y. (2008) The Effect of Six-Month Taichi Softball Ball Training on the Static Balance in Older Adults. Chinese Journal of Sports Medicine, 5, 11-19.

[22] Qi, J., Liu, M. and Zhang, S. (2009) The Effect of Taichi Softball Ball on Health in Middle-Aged Female. The Society of Chinese Scholars on Exercise Physiology and Fitness.

[23] Lam, H.S., Cheung, S.Y. and Chow, B.C. (2011) The Effect of Taiji-Soft-Ball Training on Physical Functional Health of Chinese Older Adults. Journal of Human Sport \& Exercise, 6, 540-553. https://doi.org/10.4100/jhse.2011.63.08

[24] Xiao, C.M. and Zhuang, Y.C. (2015) Effect of Taichi Ball on Balance and Physical Function in Older Adults with Type 2 Diabetes Mellitus. Journal of the American Geriatrics Society, 63, 176-177. https://doi.org/10.1111/jgs.13207

[25] Booth, A., Clarke, M., Dooley, G., Ghersi, D., Moher, D., Petticrew, M., et al. (2012) The Nuts and Bolts of PROSPERO: An International Prospective Register of Systematic Reviews. Systematic Reviews, 1, 2. https://doi.org/10.1186/2046-4053-1-2

[26] Moher, D., Shamseer, L., Clarke, M., Ghersi, D., Liberati, A., Petticrew, M., et al. (2015) Preferred Reporting Items for Systematic Review and Meta-Analysis Protocols (PRISMA-P) 2015 Statement. Systematic Reviews, 4, 1. https://doi.org/10.1186/2046-4053-4-1

[27] Lam, H.S., Cheung, S.Y. and Chow, B.C. (2011) Effect of Taichi Softball Training on Health-Related Quality of Life of Older Adults with Functional Limitation. Asian Journal of Gerontology and Geriatrics, 6, 65-71.

[28] Montgomery, D.C. (2008) Design and Analysis of Experiments. John Wiley and Sons, New York.

[29] Lai, X.H. (2010) Influence of Taiji Ball on Physical Health and Biochemical Indexes of Old People. Journal Chinese Sport Science and Technology, 122-124. 
[30] Zhang, B.X. and Li, X.X. (2012) Effect of Taichi Softball on Physical Fitness in Patients with Atherosclerosis. Tech and Guide, 32, 17.

[31] Cui, J.M. and Yang, L.N. (2012) Effect of Taiji Ball on the Estrogen, Muscle Strength and Cognitive Function of the Aging Women. China Sport Science and Technology, 48, 108-112.

[32] Higgins, J.P. and Green, S. (2011) Cochrane Handbook for Systematic Reviews of Interventions. Version 5.1.0, The Cochrane Collaboration. www.cochrane-handbook.org

[33] Qiu, X.H., Qin, Y.X. and Qiu, Z.Z. (2014) Softball and Baduanjin Comparative Study of the Body's Function of Female University Students. Fujian Sports Science and Technology, 33, 37-42.

[34] DerSimonian, R. and Laird, N. (1986) Meta-Analysis in Clinical Trials. Control Clinical Trials, 7, 177-188. https://doi.org/10.1016/0197-2456(86)90046-2

[35] Higgins, J.P., Thompson, S.G., Deeks, J.J. and Altman, D.G. (2003) Measuring Inconsistency in Meta-Analyses. BMJ, 327, 557-560. https://doi.org/10.1136/bmj.327.7414.557

[36] Xiao, C.M. (2014) Effects of Long-Term Taichi Ball Practice on Balance Performance in Older Adults. Journal of the American Geriatrics Society, 62, 984-985. https://doi.org/10.1111/jgs.12805

[37] Wei, D.L. (2012) Influence of Taiji Ball on Health Physical Fitness of Patients with Type 2 Diabetes. Journal of Nanjing Institute of Physical Education, 11, 8-11.

[38] Li, H., Wang, B. and Li, C.B. (2010) Effect of Taichi Softball on Physical Fitness in Young Adults. Journal of Neijian Normal University, 25, 95-97.

[39] Woo, J., Hong, A., Lau, E. and Lynn, H. (2007) A Randomised Controlled Trial of Tai Chi and Resistance Exercise on Bone Health, Muscle Strength and Balance in Community-Living Elderly People. Age Ageing, 36, 262-268. https://doi.org/10.1093/ageing/afm005

[40] Wang, J. (2007) Effect of Taichi Softball on Bone Mineral Density and Metabolism in Postmenopausal Period Women. Journal of Beijing Sport University, 30, 1126-1129.

[41] Jacobson, B.H., Chen, H.-C., Cashel, C. and Guerrero, L. (1997) The Effect of Tai Chi Chuan Training on Balance, Kinesthetic Sense, and Strength. Perceptual \& Motor Skills, 84, 27-33. https://doi.org/10.2466/pms.1997.84.1.27

[42] Lan, C., Lai, J.S., Chen, S.Y. and Wong, M.K. (2000) Tai Chi Chuan to Improve Muscular Strength and Endurance in Elderly Individuals: A Pilot Study. Archives of Physical Medicine and Rehabilitation, 81, 604-607. https://doi.org/10.1016/S0003-9993(00)90042-X

[43] Linke, S.E., Gallo, L.C. and Norman, G.J. (2011) Attrition and Adherence Rates of Sustained vs. Intermittent Exercise Interventions. Annals of Behavioral Medicine, 42, 197-209. https://doi.org/10.1007/s12160-011-9279-8

[44] Hacker, E.D. and Mjukian, M. (2014) Methodological Issues in Exercise Intervention Studies: Attrition and Adherence. Biology of Blood and Marrow Transplantation, 20, 195.

[45] McAuley, E., Courneya, K.S., Rudolph, D.L. and Lox, C.L. (1994) Enhancing Exercise Adherence in Middle-Aged Males and Females. Preventive Medicine, 23, 498 506. https://doi.org/10.1006/pmed.1994.1068

[46] Craig, P., Dieppe, P., Macintyre, S., Michie, S., Nazareth, I. and Petticrew, M. (2008) Developing and Evaluating Complex Interventions: The New Medical Research Council Guidance. BMJ, 337, a1655. https://doi.org/10.1136/bmj.a1655 
[47] Eccles, M., Grimshaw, J., Campbell, M. and Ramsay, C. (2003) Research Designs for Studies Evaluating the Effectiveness of Change and Improvement Strategies. Quality \& Safety in Health Care, 12, 47-52. https://doi.org/10.1136/qhc.12.1.47

Submit or recommend next manuscript to SCIRP and we will provide best service for you:

Accepting pre-submission inquiries through Email, Facebook, LinkedIn, Twitter, etc. A wide selection of journals (inclusive of 9 subjects, more than 200 journals)

Providing 24-hour high-quality service

User-friendly online submission system

Fair and swift peer-review system

Efficient typesetting and proofreading procedure

Display of the result of downloads and visits, as well as the number of cited articles Maximum dissemination of your research work

Submit your manuscript at: http://papersubmission.scirp.org/

Or contact ojpm@scirp.org 